\title{
PREVALENCE OF DIABETES AMONG TUBERCULOSIS PATIENTS AND ASSOCIATED RISK FACTORS IN KATHMANDU VALLEY
}

\author{
Thapa $B^{1}$, Paudel R², Thapa $P^{3}$, Shrestha $A^{4}$,Poudyal AK², \\ 1 Ipas Nepal, Kathmandu, Nepal \\ 2 Department of Community Medicine and Public Health, Maharajgunj Medical Campus, IOM, Kathmandu, Nepal \\ ${ }^{3}$ Nepal Health Research Council, Ramshah Path, Kathmandu, Nepal \\ 4 University of Queensland, Brisbane, Australia.
}

\begin{abstract}
Introduction: Diabetes among tuberculosis patients is a growing concern. The prevalence of diabetes among tuberculosis patients in Nepal is not known. The objective of this study was to determine the prevalence of diabetes among tuberculosis patients and to identify the associated risk factors.

Methodology: A descriptive, cross-sectional study was conducted in Kathmandu valley of Nepal. Face to face interviews using structured questionnaire were conducted to collect socio-demographic and behavioral risk factors. A random blood sugar test was carried out using glucometer. Measurements on height, weight and waist circumference were taken to obtain the anthropometric information.

Results: Out of 407 tuberculosis patients recruited in the study, 37 (9.1\%) were found to have diabetes. Among them $28(6.9 \%)$ were self reported cases of diabetes while $9(2.2 \%)$ were found with random blood sugar level $>200 \mathrm{mg} / \mathrm{dl}$. Tuberculosis patients aged 50 years and above (OR 7.5;95\% $\mathrm{Cl} 2.72-20.66)$, ever tobacco users (OR 3.5; 95\% Cl 1.19-10.74), high income status (OR 5.2; 95\% Cl 1.59-17.26) and self history of high blood pressure (OR 20.0; 95\% Cl 5.07-79.50) were found significantly associated with diabetes.
\end{abstract}

Conclusion: Overall, the prevalence of diabetes among tuberculosis patients was $9.1 \%$. Older age, tobacco use, high income status and history of high blood pressure were identified as associated risk factors.

Key words: Diabetes; Prevalence; TB; Nepal

\section{INTRODUCTION}

World Health Organization (WHO) stated that 350 million people were living with diabetes in $2011 .{ }^{1}$ It is predicted to increase by $50.0 \%$ till 2030 . The prevalence of diabetes is similar in both high and lowincome countries. Likewise, in 2011, there were 8.7 million estimated new cases of tuberculosis (TB) and 1.4 million had died from TB. ${ }^{2}$ South-East Asia and Western Pacific regions accounted for $60.0 \%$ of total TB cases. TB in Nepal remains to be a major public health problem. About $45.0 \%$ of the total population is infected with TB, of which $60.0 \%$ are adults. ${ }^{3}$

\section{Correspondence:}

Ms. Barsha Thapa

District Coordinator

Nawalparasi District, Ipas Nepal.

E-mail: barsha35@gmail.com
Diabetes leads to the faster progression of latent TB infection (LTBI) to active TB disease and poor TB treatment outcomes such as death during treatment, relapses and delayed sputum smear conversion. ${ }^{1}$ The prevalence of diabetes among TB patients varies between countries and limited evidences are drawn from low-income countries. ${ }^{4}$ Studies in several countries showed varied results regarding the prevalence of diabetes among TB patients. Some revealed $3.3 \%$ while others reported up to $44.0 \% .^{5-18}$ In Nepal, however no studies were found on prevalence of diabetes among tuberculosis patients and its associated risk factors. Thus, the aim of this study was to determine the prevalence of diabetes among tuberculosis patients and to identify the associated risk factors. 


\section{Study variables:}

Dependent variable: Diabetes among TB patients

Independent variable: Independent variables were divided into 3 major domains:

1. Socio-demographic factors (Age, Sex, Education and Income )

2. Anthropometric measurements (Body Mass Index (BMI) and waist circumference)

3. Behavioral and other risk factors (tobacco use, alcohol use, family history of diabetes, physical activity, food habit, type of TB and history of high blood pressure)

Operational definition of variables:

Diabetes: Respondent who self reported of having diabetes and/or those with random blood sugar level $>200 \mathrm{mg} / \mathrm{dl}$ at the time of the study enrollment tested by using glucometer was considered to have diabetes. ${ }^{10}$

TB patient: Respondent who was diagnosed and registered as a tuberculosis patient under National Tuberculosis Control Program and was on TB treatment during the study period.

Age: Age of the respondent was in completed years

Income: Income status of the respondents was obtained using principle component analysis method. Respondents were classified into three groups: High, Middle and Low income status. A total of 15 components were included in the analysis to find out the income status of the respondents.

Education: Respondents highest level of education. For the purpose of this study, it was classified as:

No education: Never attended school

Primary: Formal education up to five classes

Secondary: Formal education from 6-10

Intermediate $(10+2)$ or above, 12 class passed or above

Place of Residence: Those respondents who were living in VDCs and municipalities for at least more than 6 months from the interview date were classified as rural residents and urban residents respectively.

\section{Tobacco Use}

Ever user: Respondent who revealed that they had ever used tobacco products (cigarettes and/or bidis, khaini, surti, gutkha, pan with jarda and others) but was or was not using at the time of the study.

Current user: Respondent using tobacco products (cigarettes and/or bidis, khaini, surti, gutkha, pan with jarda and others) at the time of study enrollment.

\section{Alcohol Use}

Ever user: Respondent who answered that they had ever used alcohol but was or was not using at the time of the study.

Current user: Respondent using alcohol at the time of study enrollment.

Family History of Diabetes: Respondents with any one of their parents/grandparents/siblings suffered or suffering from diabetes.

Food Habit: Respondents being a vegetarian (with eggs or without eggs) and a non vegetarian.

Physical Activity: Respondents meeting WHO recommendations of 600 MET minutes per week were considered as physically active and those not meeting the recommended value were categorized as physically inactive. Metabolic Equivalent (MET) is the ratio of a person's working metabolic rate relative to the resting metabolic rate. One MET is defined as the energy cost of sitting quietly and is equivalent to a caloric consumption of $1 \mathrm{kcal} / \mathrm{kg} / \mathrm{hour} .{ }^{19}$

\section{METHODOLOGY}

Study design: A descriptive, cross-sectional study was carried out.

Study population: All TB patients aged 15 years and above who were registered under National Tuberculosis Control Program and on treatment during the study period were the study population. The association between DR TB and diabetes was found unclear, thus DR TB was excluded. ${ }^{20}$ Pregnant/lactating mothers were also excluded in the study.

Study setting: The study was conducted in Kathmandu valley comprising three districts viz. Kathmandu, Lalitpur and Bhaktapur which consists of a total of 107 DOTS units. The sites were purposively selected.

\section{Sample Size}

Sample size was calculated with following values: 
- Two sided confidence level $=95.0 \%$

- Prevalence of diabetes among tuberculosis patients = $14.0 \% 10$

- Sample size $(n)=z 2 p q / / 2$

- $n=1.96^{*} 1.96^{*} 0.14^{*} 0.86 /(.05) 2=185.01=185$

- $n=185^{\star} 2=370$ (Adding design effect 2)

- Non response rate: $10.0 \%$

- Total sample size $=407$

Sampling Design: Each DOTS unit was considered as a cluster. Out of the total 107 DOTS units in the valley, 17 DOTS units were visited which included 9 from Kathmandu, 4 from Lalitpur and 4 from Bhaktapur to get the sample of 407 participants. Seven of those visited DOTS units were hospital run clinics, 5 were municipality run urban health clinics (UHCs), 2 were health posts (HPs), 2 were primary health care centers (PHCCs) and 1 was NGO run DOTS unit.

Data collection procedure: Data was collected from $15^{\text {th }}$ of September to $23^{\text {rd }}$ of November 2013. Research Assistants visited the DOTS units and requested TB patients for participation. Those who provided verbal as well as written consent were included in the study. Face to face interviews using pretested structured questionnaire was done to collect the information on socio-demographic characteristics, behavioral and other risk factors along with a history of diabetes. For self reported diabetes, patients were asked to collect the medication slips/patient cards/diagnosis slips to ensure the confirmation of self reported diabetes. In case the DOTS center is hospital run DOTS centers and if the patient was diagnosed with diabetes in the respective hospital, laboratory records were also reviewed. Height and waist circumference were measured using non stretchable linen tape while well calibrated floor weighing scale was used to measure weight to get the anthropometric information by the trained research assistants. The measurements were used to derive the Body Mass Index (BMI) and the BMI 18.50 to $24.99 \mathrm{~kg} / \mathrm{m}^{2}$ was categorized as normal. Random capillary blood sugar test was conducted using glucometer by research assistants with clinical background (One of them is staff nurse and other is Health Assistant). The glucometer used for the purpose of this study was named Gmate Mini, a product of PHILOSYS (a korean company). Various studies showed different results for varied values in regard to the sensitivity and specificity of using glucometer for random capillary blood glucose level test. The sensitivity and specificity of a glucometer for random capillary blood sugar test for the value more than $7.8 \mathrm{mmol} / \mathrm{l}(140.4 \mathrm{mg} / \mathrm{dl})$ is $75.0 \%$ and $88.0 \%$ respectively. ${ }^{21}$ Those patients with blood sugar level $>200 \mathrm{mg} / \mathrm{dl}$ taken randomly at the time of study enrollment were considered as diabetic. ${ }^{10}$

\section{Study Instrument:}

- Interviewer administered structured questionnaire including Global Physical Activity Questionnaire (GPAQ) developed by WHO for assessing physical activity. ${ }^{19}$

- Floor weighing scale for weight, and Linen tape for height, and waist circumference measurement were used.

- Gmate Mini, a product of PHILOSYS (Glucometer) for random capillary blood sugar test.

Pretesting of questionnaire: Pretesting of questionnaire was done in Baneswor DOTS clinic. A total of 20 TB patients had undergone pretesting for diabetes. As a result minor changes were made in a questionnaire.

Ethics Statement: Approval was taken from Institutional Review Board (IRB), Institute of Medicine (IOM), Tribhuvan University, Maharajgunj, Nepal. TB patients aged 15 years and above were the study participants. Both written and verbal consent was obtained prior to the test. The consent form was priorly designed and approved from the IRB, IOM before its application in the field. The written consents obtained were kept in an individual patient files and were documented. Patients with self history of diabetes were advised on lifestyle modification measures and those found on medication for both diabetes and TB were advised to continue both medication. Patients with blood sugar level $>200 \mathrm{mg} / \mathrm{dl}$ were advised to go for the confirmatory test of diabetes. They were also notified to the respective DOTS units' in-charge for follow up.

Data management and analysis: Data was entered in EpiData 3.1 and analysis was done in three sections using Statistical Package for Social Sciences (SPSS) full version 16. Descriptive analysis was done in the form of frequencies, percentages, mean, median and standard deviation. Chi-square/fischer's exact test was done to test the association. Variables with $p$ value $<0.05$ were considered to be significant and 
were subjected to multivariate analysis. Prevalence odds ratio with confidence interval was also calculated.

\section{RESULTS}

Out of 407 TB patients enrolled in the study, 37 (9.1\%) were found to have diabetes. Of which, 28 $(6.9 \%)$ were self reported cases and $9(2.2 \%)$ were identified by the test. Twenty five (89.3\%) out of 28 self reported cases had a history of diabetes prior to the TB diagnosis while $2(7.1 \%)$ had known at the time TB was diagnosed and $1(3.6 \%)$ knew after TB was diagnosed. Major proportion of TB patients with diabetes were 50 years and above (54.0\%), male $(56.8 \%)$ and living in urban part $(94.6 \%)$ of the valley. Likewise, most of the diabetic TB patients (73.0\%) had normal Body Mass Index (BMI) (18.50$24.99) \mathrm{kg} / \mathrm{m}^{2}$ and waist circumference $<90 \mathrm{~cm}$ $(96.5 \%)$. Majority had ever used tobacco $(78.4 \%)$, were non vegetarian (91.9\%) and pulmonary TB patients (73.0\%). Under bivariate analysis, TB patients aged 50 years and above $(P=0.000)$, high income status $(P=0.000)$, waist circumference $>90 \mathrm{~cm}(P=0.000)$, ever tobacco users $(P=0.001)$, ever alcohol users $(P=0.002)$, positive family history of diabetes $(P=0.012)$, self history of high blood pressure $(P=0.000)$ and pulmonary TB $(P=0.030)$ were found associated with diabetes. However, when these variables were subjected to multivariate analysis, TB patients aged 50 years and above (Prevalence odds ratio [POR] 7.5, 95\% Cl 2.7220.66), high income status (POR 5.2, 95\% Cl 1.5917.26), ever tobacco users (POR 3.5, 95\% $\mathrm{Cl} 1.19$ 10.74 ) and self history of high blood pressure (POR $20.0,95 \% \mathrm{Cl}$ 5.07-79.50) were identified as associated risk factors of diabetes among TB patients.

\begin{tabular}{|l|l|l|}
\hline \multicolumn{3}{|l|}{ Table 1. Respondents by their diabetic status } \\
\hline Characteristics & Frequency & Percent $(\%)$ \\
\hline Diabetes $(\mathrm{n}=407)$ & 37 & 9.1 \\
\hline Yes & 370 & 90.9 \\
\hline No & \multicolumn{3}{|l|}{} \\
\hline Diabetic status $(\mathrm{n}=37)$ & 75.7 \\
\hline Self reported & 28 & 24.3 \\
\hline Random blood & 9 & 89.3 \\
\hline History of diabetes prior TB diagnosis $(\mathrm{n}=28)$ \\
\hline Yes & 25 & \\
\hline
\end{tabular}

\begin{tabular}{|l|l|l|}
\hline No & 1 & 3.6 \\
\hline Don't know & 2 & 7.1 \\
\hline
\end{tabular}

\begin{tabular}{|c|c|c|c|}
\hline $\begin{array}{l}\text { Socio- } \\
\text { demographic } \\
\text { characteristics }\end{array}$ & $\begin{array}{l}\text { TB-DM } \\
(n=37)\end{array}$ & $\begin{array}{l}\text { TB only } \\
(n=370)\end{array}$ & $\begin{array}{l}\text { Total } \\
(n=407)\end{array}$ \\
\hline \multicolumn{4}{|l|}{ Age group } \\
\hline $15-24$ & $1(2.7 \%)$ & $168(45.4 \%)$ & $168(41.3 \%)$ \\
\hline $25-34$ & $1(2.7 \%)$ & $114(30.8 \%)$ & $115(28.3 \%)$ \\
\hline $35-44$ & $9(24.3 \%)$ & $41(11.1 \%)$ & $51(12.5 \%)$ \\
\hline $45-54$ & $14(37.8 \%)$ & $24(6.5 \%)$ & $38(9.3 \%)$ \\
\hline Above 55 & $12(32.5 \%)$ & $23(6.2 \%)$ & $35(8.6 \%)$ \\
\hline Mean $\pm S D$ (yrs) & $50.1 \pm 9.2$ & $29.6 \pm 12.4$ & $31.4 \pm 13.5$ \\
\hline \multicolumn{4}{|l|}{ Sex } \\
\hline Male & $21(56.8 \%)$ & $178(48.1 \%)$ & $199(48.9 \%)$ \\
\hline Female & $16(43.2 \%)$ & $192(51.9 \%)$ & $208(51.1 \%)$ \\
\hline \multicolumn{4}{|l|}{ Education level } \\
\hline No education & $15(40.5 \%)$ & $63(17.0 \%)$ & $78(19.2 \%)$ \\
\hline Primary (1-5) & $7(18.9 \%)$ & $44(11.9 \%)$ & $51(12.5 \%)$ \\
\hline $\begin{array}{l}\text { Secondary } \\
(6-10)\end{array}$ & $13(35.1 \%)$ & $178(48.1 \%)$ & $191(46.9 \%)$ \\
\hline $\begin{array}{l}\text { Intermediate } \\
\text { level }(10+2) \\
\text { and above }\end{array}$ & $2(5.4 \%)$ & $85(23.0 \%)$ & $87(21.4 \%)$ \\
\hline \multicolumn{4}{|c|}{ Place of residence } \\
\hline Rural & $2(5.4 \%)$ & $44(11.9 \%)$ & $46(11.3 \%)$ \\
\hline Urban & $35(94.6 \%)$ & $326(88.1 \%)$ & $361(88.7 \%)$ \\
\hline
\end{tabular}

\begin{tabular}{|l|l|l|l|}
\hline $\begin{array}{l}\text { Table 3. Respondents by their anthropometric } \\
\text { characteristics }\end{array}$ \\
\hline $\begin{array}{l}\text { Anthropometric } \\
\text { characteristics }\end{array}$ & $\begin{array}{l}\text { TB-DM } \\
(\mathrm{n}=37)\end{array}$ & $\begin{array}{l}\text { TB only } \\
(\mathrm{n}=370))\end{array}$ & $\begin{array}{l}\text { Total } \\
(\mathrm{n}=407)\end{array}$ \\
\hline BMI & $5(13.5 \%)$ & $103(27.8 \%)$ & $108(26.5 \%)$ \\
\hline $\begin{array}{l}\text { Underweight } \\
(<18.5 \mathrm{~kg} / \mathrm{m} 2)\end{array}$ & $27(73.0 \%)$ & $231(62.5 \%)$ & $258(63.4 \%)$ \\
\hline $\begin{array}{l}\text { Normal }(18.5- \\
24.99) \mathrm{kg} / \mathrm{m} 2\end{array}$ & $5(13.5 \%)$ & $36(9.7 \%)$ & $41(10.1 \%)$ \\
\hline $\begin{array}{l}\text { Overweight } \\
(>24.99 \mathrm{~kg} / \mathrm{m} 2)\end{array}$ & & & \\
\hline Waist circumference & & \\
\hline Low $(<90 \mathrm{cms})$ & $357(96.5 \%)$ & $29(78.4 \%)$ & $368(94.8 \%)$ \\
\hline High (>90 cms) & $13(13.5 \%)$ & $8(21.6 \%)$ & $21(5.2 \%)$ \\
\hline
\end{tabular}




\begin{tabular}{|l|l|l|l|}
\hline Mean \pm SD $(\mathrm{cms})$ & $83.8 \pm 7.9$ & $76.5 \pm 7.3$ & $77.2 \pm 7.6$ \\
\hline
\end{tabular}

\begin{tabular}{|l|l|l|l|}
\hline $\begin{array}{l}\text { Table 4. Respondents by their behavioral characteristics } \\
\text { and other risk factors }\end{array}$ \\
\hline Characteristics & $\begin{array}{l}\text { TB-DM } \\
(\mathrm{n}=37)\end{array}$ & $\begin{array}{l}\text { TB only } \\
(\mathrm{n}=370)\end{array}$ & $\begin{array}{l}\text { Total } \\
(\mathrm{n}=407)\end{array}$ \\
\hline Tobacco use (Ever used) & $29(78.4 \%)$ & $112(30.3 \%)$ & $141(34.6 \%)$ \\
\hline Yes & $8(21.6 \%)$ & $258(69.7 \%)$ & $266(65.4 \%)$ \\
\hline No
\end{tabular}

Alcohol use (Ever use )

\begin{tabular}{|l|l|l|l|}
\hline Yes & $22(59.5 \%)$ & $102(27.6 \%)$ & $124(30.5 \%)$ \\
\hline No & $15(40.5 \%)$ & $268(72.4 \%)$ & $283(69.5 \%)$ \\
\hline
\end{tabular}

Food habit

\begin{tabular}{|l|l|l|l|}
\hline Vegetarian & $3(8.1 \%)$ & $31(8.4 \%)$ & $34(8.4 \%)$ \\
\hline Non-vegetarian & $34(91.9 \%)$ & $339(91.6 \%)$ & $373(91.6 \%)$ \\
\hline
\end{tabular}

Physical activity

\begin{tabular}{|l|l|l|l|}
\hline Physically active & $19(51.4 \%)$ & $230(62.2 \%)$ & $249(61.2 \%)$
\end{tabular}

( $\geq 600 \mathrm{MET}$

minutes/week)

\begin{tabular}{|l|l|l|l|}
\hline Physically & $18(48.6 \%)$ & $140(37.8 \%)$ & $158(38.8 \%)$
\end{tabular}

inactive

$(<600 \mathrm{MET}$

minutes/week)

Median minutes spent on sedentary activities per day ${ }^{*}=120$

minutes

Self history of High blood pressure

\begin{tabular}{|l|l|l|l|}
\hline Yes & $16(43.2 \%)$ & $8(2.2 \%)$ & $24(5.9 \%)$ \\
\hline No & $21(56.8 \%)$ & $362(97.8 \%)$ & $383(94.1 \%)$ \\
\hline
\end{tabular}

Family history of diabetes

\begin{tabular}{|l|l|l|l|}
\hline Yes & $9(24.4 \%)$ & $30(8.1 \%)$ & $39(9.6 \%)$ \\
\hline
\end{tabular}

\begin{tabular}{|l|l|l|l|}
\hline No & $24(64.8 \%)$ & $313(84.6 \%)$ & $337(82.8 \%)$ \\
\hline
\end{tabular}

\begin{tabular}{|l|l|l|l|}
\hline Don't know & $4(10.8 \%)$ & $27(7.3 \%)$ & $31(7.6 \%)$ \\
\hline
\end{tabular}

Type of TB

\begin{tabular}{|l|l|l|l|}
\hline PTB & $27(73.0 \%)$ & $203(54.9 \%)$ & $230(56.5 \%)$ \\
\hline
\end{tabular}

\begin{tabular}{|l|l|l|l|}
\hline EPTB & $10(27.0 \%)$ & $167(45.1 \%)$ & $177(43.5 \%)$ \\
\hline
\end{tabular}

${ }^{*}$ Sedentary activities include sitting, watching TV, reading books and other idle activities while sleeping is not inclusive.

Table 5. Results from bivariate analysis

\begin{tabular}{|l|l|l|l|}
\hline Variables & $\begin{array}{l}\text { TB-DM } \\
(\mathrm{n}=37)\end{array}$ & $\begin{array}{l}\text { TB only } \\
(\mathrm{n}=370)\end{array}$ & $\mathrm{P}$ value \\
\hline Age group \\
\hline$<50$ years & 17 & 336 & $0.000^{*}$ \\
\hline$\geq 50$ years & 20 & 34 & \\
\hline Sex & 16 & 192 & 0.381 \\
\hline Female & 16 & 178 & \\
\hline Male & 21 & \\
\hline Place of residence
\end{tabular}

\begin{tabular}{|l|l|l|l|}
\hline Rural & 2 & 44 & $0.410^{\mathrm{a}}$ \\
\hline Urban & 35 & 326 & \\
\hline BMl & & 103 & 0.121 \\
\hline $\begin{array}{l}\text { Underweight } \\
(<18.5)\end{array}$ & 5 & 231 & \\
\hline $\begin{array}{l}\text { Normal (18.5 - } \\
\text { 24.99) }\end{array}$ & 27 & 36 & \\
\hline $\begin{array}{l}\text { Overweight } \\
(>24.99)\end{array}$ & 5 & & \\
\hline
\end{tabular}

\section{Waist circumference}

\begin{tabular}{|l|l|l|l|}
\hline$<90 \mathrm{cms}$ & 29 & 357 & $0.000^{\star *}$ \\
\hline$\geq 90 \mathrm{cms}$ & 8 & 13 & \\
\hline Income status \\
\hline Low & 5 & 131 & $0.000^{*}$ \\
\hline Middle & 5 & 130 & \\
\hline High & 27 & 109 & \\
\hline
\end{tabular}

\section{Ever tobacco users}

\begin{tabular}{|l|l|l|l|}
\hline No & 8 & 258 & $0.001^{*}$ \\
\hline Yes & 29 & 112 & \\
\hline
\end{tabular}

\section{Ever alcohol users}

\begin{tabular}{|c|c|c|c|}
\hline No & 15 & 268 & $0.002^{*}$ \\
\hline Yes & 22 & 102 & \\
\hline \multicolumn{4}{|l|}{ Food habit } \\
\hline Vegetarian & 3 & 31 & $1.001^{a}$ \\
\hline $\begin{array}{l}\text { Non } \\
\text { vegetarian }\end{array}$ & 34 & 339 & \\
\hline
\end{tabular}

\section{Physical activity}

\begin{tabular}{|l|l|l|l|}
\hline $\begin{array}{l}\text { Physically } \\
\text { active }\end{array}$ & 230 & 19 & 0.213 \\
\hline $\begin{array}{l}\text { Physically } \\
\text { inactive }\end{array}$ & 140 & 18 & \\
\hline
\end{tabular}

\section{Family history of diabetes}

\begin{tabular}{|l|l|l|l|}
\hline No & 24 & 313 & $0.012^{\text {a* }}$ \\
\hline Yes & 9 & 30 & \\
\hline Don't know & 4 & 27 & \\
\hline History of high blood pressure \\
\hline No & 21 & 362 & $0.000^{\text {a* }}$ \\
\hline Yes & 16 & 8 & \\
\hline \multicolumn{5}{|l|}{ Type of TB } \\
\hline Pulmonary TB & 27 & 203 & $0.030^{*}$ \\
\hline $\begin{array}{l}\text { Extra- } \\
\text { pulmonary TB }\end{array}$ & 10 & 167 & \\
\hline
\end{tabular}

${ }^{\text {a }}$ Fischer exact test value, ${ }^{*} \mathrm{P}$ value $<0.05$

\begin{tabular}{|l|l|l|l|}
\hline \multicolumn{4}{|c|}{ Table 6. Results from multivariate analysis } \\
\hline & $\begin{array}{l}\text { TB-DM } \\
(n=37)\end{array}$ & $\begin{array}{l}\text { TB only } \\
(n=370)\end{array}$ & POR $(95 \% \mathrm{Cl})^{*}$ \\
\hline Age group \\
\hline$\geq 50$ yrs & $20(54.0)$ & $34(9.2)$ & $7.5(2.72-20.66)$ \\
\hline
\end{tabular}




\begin{tabular}{|l|l|l|l|}
\hline$<50$ yrs & $17(46.0)$ & $336(90.8)$ & Reference \\
\hline Income status \\
\hline High & $27(73.0)$ & $109(29.8)$ & $5.2(1.59-17.26)$ \\
\hline Middle & $5(13.5)$ & $130(35.1)$ & $0.9(0.22-3.99)$ \\
\hline Low & $5(13.5)$ & $131(35.1)$ & Reference \\
\hline Waist circumference \\
\hline <90 cms & $357(96.5)$ & $29(78.4)$ & $2.2(0.47-10.34)$ \\
\hline$>90$ cms & $13(13.5)$ & $8(21.6)$ & Reference \\
\hline Tobacco use & & \\
\hline Ever & $29(78.4)$ & $112(30.3)$ & $3.5(1.19-10.74)$ \\
\hline Never & $8(21.6)$ & $258(69.7)$ & Reference \\
\hline Alcohol use & \multicolumn{5}{|l}{} \\
\hline Ever & $22(59.5)$ & $102(27.6)$ & $1.1(0.40-3.11)$ \\
\hline Never & $15(40.5)$ & $268(72.4)$ & Reference \\
\hline Self history of high blood pressure \\
\hline Yes & $16(43.2)$ & $8(2.2)$ & $20.0(5.07-79.50)$ \\
\hline No & $21(56.8)$ & $362(97.8)$ & Reference \\
\hline Family history of diabetes \\
\hline Yes & 9 (24.4) & $30(8.1)$ & $2.8(0.70-11.20)$ \\
\hline Don't know & $4(10.8)$ & $27(7.3)$ & $2.4(0.60-10.38)$ \\
\hline No & $24(64.8)$ & $313(84.6)$ & Reference \\
\hline Type of TB & $27(73.0)$ & $203(54.9)$ & $2.1(0.76-6.07)$ \\
\hline Pulmonary & $10(27.0)$ & $167(45.1)$ & Reference \\
\hline $\begin{array}{l}\text { Extra- } \\
\text { pulmonary }\end{array}$ & \multicolumn{5}{|l}{} \\
\hline
\end{tabular}

NA= Not Applicable; DM = Diabetes Mellitus; POR = Prevalence Odds Ratio; $\mathrm{Cl}=$ Confidence Interval; Reference assigned for the reference category for categorical variables.

\section{DISCUSSION}

This is the first study conducted in Nepal aimed to determine the prevalence of diabetes among TB patients and to identify the associated risk factors to our knowledge. A total of 37 out of $407(9.1 \%)$ TB patients in the study were found to have diabetes. This proportion was found lower than those of screening studies in India ${ }^{17}$ and China, ${ }^{14}$ however, it was found consistent with North India. ${ }^{17}$ Self reported diabetic TB patients $(89.3 \%)$ provided a known history of diabetes prior to the diagnosis of TB with a

mean duration of 49 months. A systematic review of 13 observational studies have discussed that people with diabetes for longer period can have impaired immune responses required to oppose the progression of $\mathrm{TB}^{22}$ but the study had not talked on duration of diabetes. This could be one of the possible explanations behind having higher proportion of previously known diabetes, however, there are no evidences about diabetes preceding TB or vice-versa. ${ }^{23}$ Moreover, this can also be described with the observation that most $(88.7 \%)$ of the TB patients were from urban part of the valley with easy access to diagnostic facilities. Older age is found consistently linked to diabetes $6-9,12,13,16,18$ which was also observed in this study. The consistent linkage found could be illustrated with the fact that type II diabetes is often seen in older age. This study did not distinguish between type I and type II diabetes but has mostly considered type II diabetes, since the mean age of diabetic TB patients was 50.1 years while of those non diabetic TB patients was 29.6 years. High income status was also found associated with diabetes. We can expect that high income group of people have better, easy and early access to diagnostic and medical facilities. The amount of time spent in sedentary activities is positively associated with less glucose metabolic profile leading to higher risk of developing type II diabetes. On the contrary, increased physical activity causes increased peripheral insulin sensitivity which leads to more glucose uptake by muscles. ${ }^{24}$ A systematic review on adult sedentary behavior ${ }^{25}$ revealed that high income group will more likely to spent ample amount of time in sedentary activities. Interestingly, high income group of TB patients in this study was found spending longer time (164 minutes) compared to low income group (135 minutes) on sedentary activities. This observation could possibly describe the association, however, further research need to be done to make a relevant explanation. Likewise, tobacco use including smoking was also found significant with diabetes among TB patients. Smoking results in inflammation and oxidative stress in the body cells. Evidence showed that both inflammation and oxidative stress is related to the increased risk of diabetes. Smokers have $30.0 \%$ to $40.0 \%$ increased risk of developing diabetes compared to non 
smokers. ${ }^{26}$ In the study, it is observed that majority of diabetic TB patients $(78.3 \%)$ had ever used tobacco products including smoking compared to non diabetic TB patients (30.3\%). Also a prevalence based cohort study (2000-2005) for diabetes among TB patients in Saudi Arabia $^{15}$ showed the association as well. Studies identifying tobacco use as a risk factor for type II diabetes ${ }^{27,28}$ and for TB $^{29}$ had explained the positive association. . Accordingly, self history of high blood pressure was also identified as a predictor of diabetes among TB patients. This can be expressed in the studies which concluded that people with diabetes are more likely to have high blood pressure. ${ }^{30}$ More significantly, prospective research might justify the relationship.

\section{CONCLUSION}

The prevalence of diabetes among TB patients in our study was $9.1 \%$. The associated risk factors identified were older age, high income status, tobacco use and hypertension. It suggests for the universal screening of TB patients for diabetes.

\section{Acknowledgements}

We are indebted to Department of Community Medicine and Public Health, Maharajgunj Medical Campus, Institute of Medicine (IOM), Kathmandu, Nepal. We would like to thank research assistants Ms. Anjana Pandey and Ms. Babita Pokharel, National Tuberculosis Center (NTC) Thimi, Bhaktapur, District Public Health Officer/s (DPHOs) and District TB/Leprosy Officers (DTLOs) in Kathmandu valley, respective DOT centres in-charge and all TB patients who participated in the study.

\section{REFERENCES}

1. World Health Organization. Tuberculosis and Diabetes 2011. Geneva. Available: http://www.who.int/tb/publications/factsheets. Accessed 19th July 2013.

2. World Health Organization. Global Tuberculosis Report 2012. World Health Organization, Geneva, Switzerland.

3. MOHP/DOHS (Nepal). Annual Report, Department of Health Services 2068/69. Kathmandu, Nepal.

4. World Health Organization. Collaborative Framework for care and control of tuberculosis and diabetes. WHO Report 2011. WHO/HTM/TB/2011.15. Geneva, Switzerland.
5. B. Alisjahbana RvC, E. Sahiratmadja, M. den Heijer, A. Maya, E. Istriana, H. Danusantoso THMO, R. H. H. Nelwan, J. W. M. van der Meer. Diabetes mellitus is strongly associated with tuberculosis in Indonesia. Int J Tuberc Lung Dis 2006;(6):696-700.

6. Balde NM, Camara A, Camara LM, Diallo MM, Kake A, Bah-Sow OY. Associated tuberculosis and diabetes in Conakry, Guinea: prevalence and clinical characteristics. Int $\mathrm{J}$ Tuberc Lung Dis. 2006;10(9):1036-40.

7. Bachti Alisjahbana ESea. The Effect of Type 2 Diabetes Mellitus on the Presentation and Treatment Response of Pulmonary Tuberculosis. Clinical Infectious Diseases. 2007;45:428-35.

8. Restrepo BI, Fisher-Hoch SP, Crespo JG et al. Type 2 diabetes and tuberculosis in a dynamic bi-national border population. Epidemiol Infect. 2007;135(3):48391.

9. Ahmed $\mathrm{N}$, Faurholt-Jepsen $\mathrm{D}$, Range $\mathrm{N}$ et al. Diabetes Is a Risk Factor for Pulmonary Tuberculosis: A Case-Control Study from Mwanza, Tanzania. PLoS One. 2011;6(8):24215.

10. Alladin B, Mack S, Singh A et al. Tuberculosis and diabetes in Guyana. International Journal of Infectious Diseases. 2011;15(12):818-21.

11. Restrepo BI, Camerlin AJ, Rahbar MH et al. Crosssectional assessment reveals high diabetes prevalence among newly-diagnosed tuberculosis cases. Bull World Health Organization. 2011;89(5):352-9.

12. Al. SBe. High Diabetes Prevalence among Tuberculosis Cases in Kerala, India. PLoS Med. 2012;7(10).

13. Faurholt-Jepsen D, Range N, PrayGod G et al. The role of anthropometric and other predictors for diabetes among urban Tanzanians with tuberculosis. The International Journal of Tuberculosis and Lung Diasese. 2012;16(12):1680-5.

14. Li L, Lin $Y, M i F$ et al. Screening of patients with tuberculosis for diabetes mellitus in China. Tropical Medicine \& International Health. 2012;17(10):1294301.

15. Suleiman. SAS, Aweis. DMI, JimaleMohamed. A, RazakMuttalif. A, A. M, A.Moussa. Role of diabetes in prognosis and therapeutic outcomes of tuverculosis. International Journal of Endocrinology. 2012.

16. Viswanathan. V, Kumpatla S, Aravindalochanan V et al. Prevalence of diabetes and pre-diabetes and associated risk factors among tuberculosis patients in India. PLoS One. 2012;7(7):41367.

17. Group IT-DS. Screening of patients with tuberculosis for diabetes mellitus in India. Tropical Medicine and International Health. 2013;18(5):636-45. 
18. Olayinka A, Anthonia O, Yetunde K. Prevalence of diabetes mellitus in persons with tuberculosis in a tertiary health centre in Lagos, Nigeria. Indian Journal of Endocrinology and Metabolism. 2013;17(3):486.

19. World Health Organization. Global Physical Activity Analysis Guide 2011. Geneva.

20. S-E. Ottmani MBM, †† C. Y. Jeon, $†$ M. A. Baker, $† \S A$. Kapur, ๆ K. Lönnroth, ${ }^{*}$ A. D. Harries\#, ${ }^{* *}$. Consultation meeting on tuberculosis and diabetes mellitus:meeting summary and recommendations. INT J TUBERC LUNG DIS 2010;14(12):1513-7.

21. WHO. Report on Screening for Type 2 Diabetes 2003. World Health Organization. Geneva.

22. Jeon Christie $Y$ MMB. Diabetes mellitus increases the risk of active tuberculosis: A systematic review of 13 observational studies. PLoS Med. 2008;5(7):152.

23. Tiyas Sen* SRJ, Zarir F Udwadia*. Tuberculosis and Diabetes Mellitus: Merging Epidemics. JAPI. 2009;57.

24. Smidt Hansen, Anne-Louise, Dahl-Petersen, Inger. Physical activity and T2DM [internet]. 2014 Aug 13; Diapedia 3104466174 rev. no. 10. Available from: http://dx.doi.org/10.14496/dia.3104466174.10
25. Rhodes RE, Mark RS, Temmel CP. Adult sedentary behavior: a systematic review. Am J Prev Med. 2012;42(3):3-28.

26. Center for Disease Control and Prevention (CDC). Smoking and Diabetes. Available: http://www.cdc.gov/tobacco/data_statistics/sgr/50thanniversary/pdfs/fs__smoking_ diabetes_508.pdf. Accessed 31st Aug 2014.

27. CDC. Report on How Tobacco smoke cause disease 2010. Center for Disease Control Division.

28. S. GOYA WANNAMETHEE P, A. GERALD SHAPER F, IVAN J. PERRY F, 2 M. Smoking as a Modifiable Risk Factor for Type 2 Diabetes in Middle-Aged Men. Diabetes Care 2001;24:1590-5.

29. World Health Organization. Tuberculosis and Tobacco. Geneva. Available:http://www.who.int/entity/tobacco/publication s/health_effects/fact_sheet_tb_tobacco._Accessed $5^{\text {th }}$ January 2014.

30. Sahay BK, Sahay RK. Hypertension in diabetes. J Indian Med Assoc. 2003Jan;101(1):12,4-5,44. 